\title{
Study on Effect of Perforation Orientation on Hydraulic Fracturing of Shale
}

\author{
Jian Li, ${ }^{1}$ Dong Wang, ${ }^{1}$ Hongjian Wang $\mathbb{D}^{1,2}$ Fei Zhao $\mathbb{D}^{2},{ }^{2}$ Qingqing Ma, ${ }^{1}$ Qi Qiao, \\ and Zhiyang Yao ${ }^{1}$ \\ ${ }^{1}$ Sinopec Zhongyuan Oilfield Branch, Puyang, 457001 Henan, China \\ ${ }^{2}$ North China University of Water Resources and Electric Power, Zhengzhou, 450045 Henan, China \\ Correspondence should be addressed to Hongjian Wang; 493508184@qq.com and Fei Zhao; zhaofei_183@126.com
}

Received 8 November 2021; Accepted 16 February 2022; Published 3 March 2022

Academic Editor: Bing Hou

Copyright ( 2022 Jian Li et al. This is an open access article distributed under the Creative Commons Attribution License, which permits unrestricted use, distribution, and reproduction in any medium, provided the original work is properly cited.

\begin{abstract}
The core technology to realize the development of unconventional oil and gas resources is the large-scale volume transformation of shale reservoirs, but volume fracturing is a complex physical and mechanical process, and its mechanism remains to be further studied. In this paper, starting from the current research status of shale volumetric fracturing, the perforation orientation of volumetric fracturing is numerically simulated by using the finite element software. The following conclusions are drawn: (1) when the ground stress conditions are equal, with the increase of perforation angle, the maximum principal stress at the front of perforation decreases gradually; that is, when the perforation is along the horizontal minimum principal stress, the maximum principal stress at the front of perforation is the largest, which is most conducive to fracturing of shale reservoirs. (2) When the perforation is along the direction of the horizontal minimum principal stress and the horizontal stress difference is zero, the smaller the horizontal stress, the greater the maximum principal stress at the front of the perforation. Therefore, the smaller the horizontal stress, the more conducive to the rupture of shale reservoirs. (3) When the perforation is along the horizontal minimum principal stress, the maximum principal stress at the front of the perforation increases with the increase of the horizontal stress difference. Therefore, the larger the horizontal stress difference, the more favorable for the fracture of shale reservoirs.
\end{abstract}

\section{Introduction}

1.1. Research Status of Hydraulic Fracturing. Large-scale hydraulic fracturing technology is the core technology to realize the development of unconventional oil and gas resources. Foreign fracturing technology mainly includes [1-4] the following: nitrogen foam fracturing technology, the technology first began in January 1968, in the United States and Canada on the extensive use of foam fracturing technology, and foam fracturing is particularly suitable for low pressure and low permeability water sensitive formation [5]; water fracturing technology, which uses water to add appropriate drag reduction agent as fracturing fluid, can save $30 \%$ of the cost without reducing production and has achieved good application results in the transformation of low permeability reservoirs [6]; and synchronous fracturing technology is the latest fracturing technology which has been successfully applied in the development of Barnett shale gas in Vosburg Basin in recent years. It is the fracturing of two wells (or more than two wells) at the same time [7]. Repeated fracturing technology, which can reconstruct the linear seepage from reservoir to wellbore, restore or increase productivity, increase the final recovery rate by $8 \% \sim 10 \%$, and increase the recoverable reserves by $60 \%$, is a low-cost production increase method. Hydrojet fracturing is a hydraulic fracturing technology integrating hydraulic perforation, fracturing, and isolation. The biggest advantage of this technology is that it maintains low wellbore pressure without using sealing elements and can quickly and accurately open multiple fractures, which successfully solves the problem of hydraulic fracturing in open hole completion. Horizontal well-staged fracturing technology can effectively generate fracture network, improve ultimate recovery factor as much as possible, and save costs. The Tipton- $1 \mathrm{H}-23$ well 
located in the Woodford shale gas accumulation belt of the Akoma Basin in the United States has been transformed by 7 hydraulic fracturing measures. The shale gas production is as high as $14.16 \times 10^{4} \mathrm{~m}^{3} / \mathrm{d}[8]$.

The core technology of unconventional oil and gas resources development is large-scale volume fracturing of ultralow permeability reservoirs. As the core technology of commercial exploitation of shale gas, the application of volume fracturing theory and method has attracted the attention of engineers and peer scholars at home and abroad and has done a lot of scientific research in theory and experiment.

As early as 1981, Professor Huang Rongzun, a famous oil and gas geology expert in China, applied the linear elastic fracture mechanic theory to put forward the initiation criteria of vertical and horizontal fractures and various factors affecting the fracture propagation direction [9]. Chen et al. (2000) [10] used the large-scale true triaxial simulation test system to simulate the formation conditions, carried out the indoor simulation experiment of crack propagation on natural rocks and artificial models, realized the monitoring of the actual physical process of crack propagation, and discussed the influence of geostress, fracture toughness, joints, and natural fracture on crack propagation. Fisher et al. (2002) [11, 12] began to discuss the creation of large pressure fracture network in Barnett shale development area and initially proposed the influence of reservoir reconstruction scale size, fracture network size, and shape on shale gas production. Through field microseismic monitoring technology, it is preliminarily confirmed that the size of pressure fracture network is closely related to the volume of the reconstructed reservoir. Mayerhofer et al. (2008) [13] first proposed the concept of stimulated reservoir volume (SRV) when studying the microseismic technology and fracturing fracture changes of Barnett shale. The main factors affecting SRV include shale thickness, direction and size of ground stress field, natural fracture development, fracturing resistance, rock brittleness, and geological characteristics, such as faults and karst topography. The calculation formula for evaluating the total fracturing length of SRV is put forward:

$$
L_{f \text { total }}=\frac{4 x_{f} x_{n}}{\Delta x_{s}}+2 x_{f}+x_{n}
$$

which $L_{f \text { total }}$ is the total reservoir fracturing length, $x_{f}$ is the half length of fracture network, $x_{n}$ is the width of fracture network, and $\Delta x_{s}$ is the fracture spacing. Domestic scholar $\mathrm{Wu}$ et al. [14] proposed the basic definition of "volume transformation" and the new concept of crack initiation and propagation based on the existing research abroad. The proposal of volume fracturing is based on the new modern theory of volume stimulation. It refers to the continuous expansion of natural fractures and the shear slip of brittle rocks in the process of hydraulic fracturing, forming a fracture network in which natural fractures and artificial fractures intersect, thereby increasing the stimulation volume and improving the initial production and final recovery.
Xie et al. [15] realized the fine description of oil and gas storage and transportation in shale by fractal reconstruction and made shale embrittlement and high body fracture by using high energy thermal coupling gas. On this basis, pneumatic fracturing technology and polymer hollow thermal expansion support technology were proposed, which were different from conventional shale reservoir reconstruction methods.

1.2. Research Status of Numerical Simulation of Hydraulic Fracturing. Computer technology has played a vital role in scientific research and industrial development. The application of numerical simulation technology in the process of shale gas exploitation to achieve the visualization of largescale volume fracturing process is helpful to further study the mechanism of volume fracturing and optimize the fracturing design. The representative research at home and abroad mainly includes the following: Al-Busaidi et al. [16] used the discrete element software PFC2 D to simulate the initiation mechanism and acoustic emission distribution characteristics of hydraulic fracturing cracks. The results show that the temporal and spatial expansion characteristics of cracks are closely related to the properties of rock samples and natural cracks. The tensile failure mainly occurs in the specimens, and only a small part of the shear slip occurs. Adachi et al. (2007) [17] summarized and discussed the standard method and propagation mechanism for controlling the hydraulic fracturing process, introduced the mathematical equation and boundary conditions for controlling the fracturing propagation, and systematically introduced the fracture propagation path and its control factors in the numerical calculation process, including time function, coupling equation, and time step program. Domestic scholar Zhu et al. [18] used the finite element method to simulate the three-dimensional fracture dynamic propagation of hydraulic fracturing in low permeability reservoirs, realized the dynamic description of the three-dimensional fracture formation process of low permeability reservoirs, and simulated the Zhao 38-271 well. Some scientists investigate the fracture modes using XFEM and acoustic emissions $[19,20]$. Hamidi et al. (2013) [21] used three-dimensional discrete element software 3DEC to simulate the initiation and propagation of volume fracturing fractures. The results show that the successful volume fracturing depends not only on the characteristics of fracturing fluid and injection rate but also on the in situ stress state, the size and direction of principal stress, and rock mechanical properties that are not controlled by human factors. Ahn et al. (2014) [22] established an improved and effective numerical model to simulate the initiation and propagation characteristics of hydraulic fracturing cracks in shale reservoirs with natural fractures and studied the hydraulic fracturing process under natural joints, fracturing fluid filtration, and fluid flow, so as to further optimize the field fracturing design.

Most of the previous numerical simulation of hydraulic fracturing are the condition of two-dimensional plane and rarely reproduce the fracture initiation and propagation path in three-dimensional space [23-38]. In the future, the numerical analysis and research should be combined with 


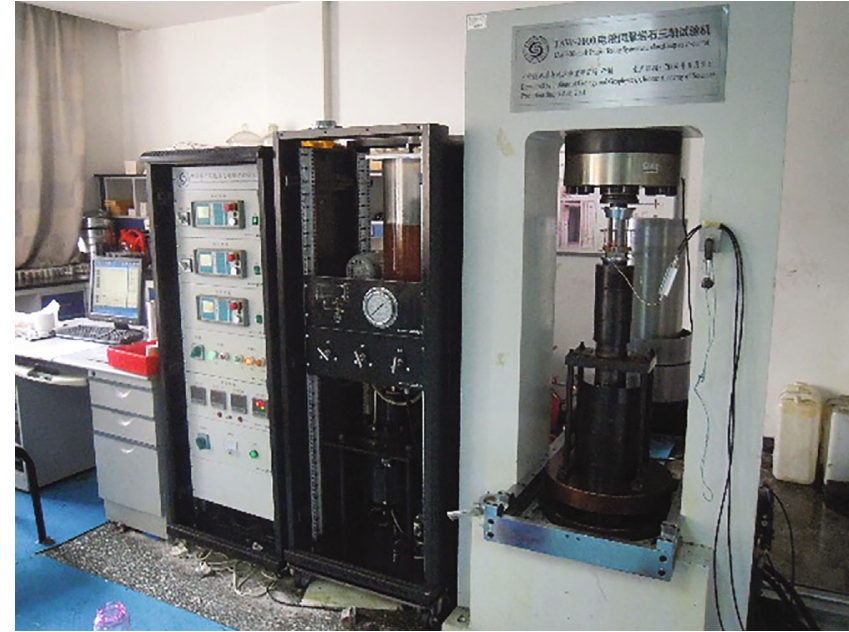

(a) TAW-2000

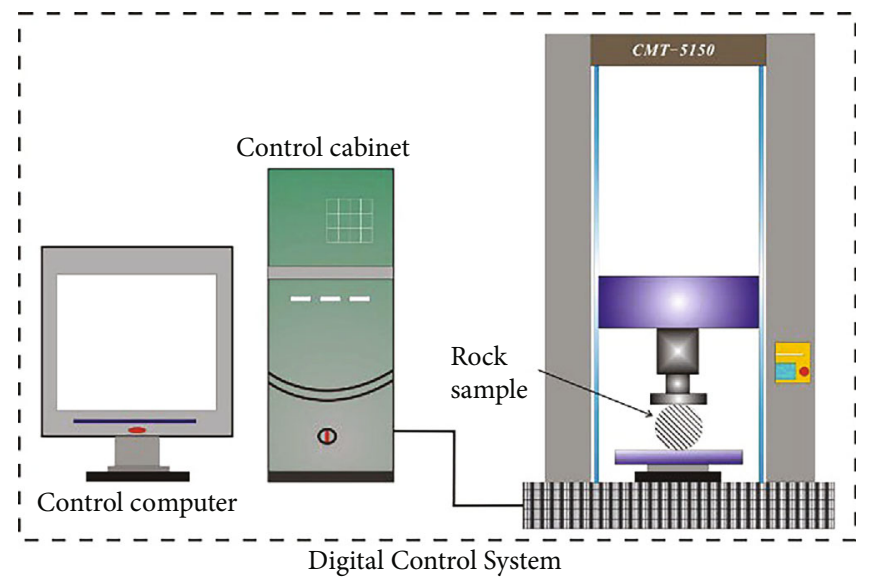

(b) CMT-5150

FIGURE 1: Rock mechanic test system.

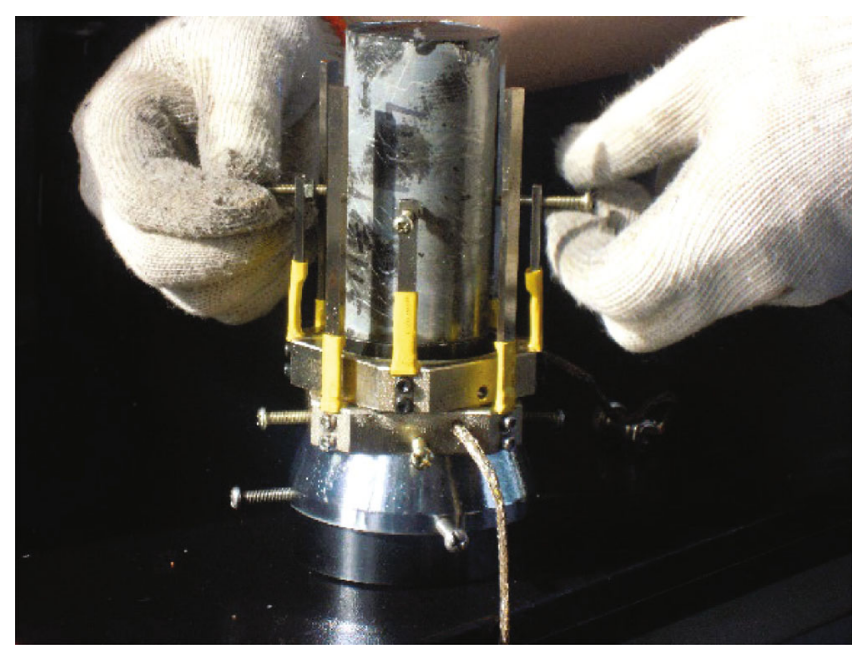

Figure 2: Uniaxial compression test of shale rock.

the actual geological engineering conditions to establish a more realistic three-dimensional numerical model, fully consider the various factors affecting the fracturing effect in the real situation, provide reliable data support for large-scale volume fracturing, and optimize the fracturing design.

\section{Establishment of the Finite Element Model for Volume Fracturing Numerical Calculation}

At present, the finite element method (FEM) has received high attention and has been widely used in scientific research and practical engineering. It is because the FEM has higher reliability and accuracy compared with other methods [39-42].

The main purpose of this section is to extend the conclusions obtained from the indoor volumetric fracturing test and numerical simulation to shale reservoir. Through numerical simulation of hydraulic fracturing process of shale reservoir, the influence of different factors on hydraulic fracturing process of shale reservoir is studied. This paper mainly studies the effect of perforation angle on fracturing. According to geological survey data and indoor physical and mechanical experiment (Figures 1-3), the relevant data of black carbonaceous shale formation in the dragon stream formation are as follows: the buried depth in the middle of the reservoir is about $2500 \mathrm{~m}$, the mean elastic modulus is $35 \mathrm{GPa}$, the mean Poisson's ratio is 0.25 , the internal friction angle is 33.86 , the cohesion is $8.98 \mathrm{MPa}$, the permeability coefficient is $2 \times 10^{-9} \mathrm{~m} / \mathrm{s}$, the initial pore pressure is 26.25 MPa, the horizontal minimum in situ stress is $46.25 \mathrm{MPa}$, and the horizontal maximum in situ stress is $52.5 \mathrm{MPa}$. The stress of overlying strata is $50 \mathrm{MPa}$. At the beginning of hydraulic fracturing site construction, about $1 \mathrm{~m}^{3} / \mathrm{min}$ of fracturing fluid is injected, and the formation is fractured with the displacement of $2-5 \mathrm{~m}^{3} / \mathrm{min}$. After that, the displacement is increased to $10-15 \mathrm{~m}^{3} / \mathrm{min}$ 


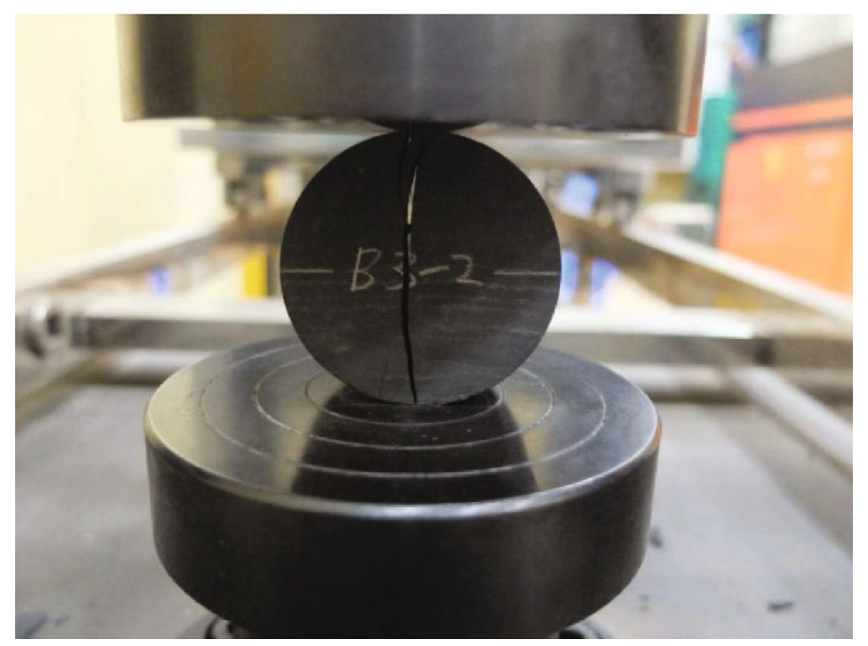

FIGURE 3: Brazilian splitting test of shale rock.

to increase the scale of fracture network. The pumping time is about $200 \mathrm{~min}$, the fracturing fluid volume is $2000 \mathrm{~m}^{3}$, and the length of a single hydraulic fracture is about $250 \mathrm{~m}$. The Morh-Coulomb model is used in this simulation, and the simulation is carried out according to the above parameters.

First, enter the Part module to establish the reservoir model. The length, width, and height of the simulated shale reservoir are $6 \mathrm{~m} \times 6 \mathrm{~m} \times 0.5 \mathrm{~m}$, respectively, and the model is named "Shale Reservoir," 3D variable shape, and solid type. Use the extrusion function to create a $6 \mathrm{~m} \times 6 \mathrm{~m} \times 0.5 \mathrm{~m}$ cuboid. The diameter of the well is $1 \mathrm{~m}$, a circle with radius of $0.5 \mathrm{~m}$ is drawn on the upper surface of the model by partition command, and then a cylinder with diameter of $1 \mathrm{~m}$ and height of $0.5 \mathrm{~m}$ is cut out at the center of the model by partition cell: extrude edge command and name this cylinder as a collection "Well." The perforation radius is 0.5 in $(12.7 \mathrm{~mm})$, and the perforation length is $120 \mathrm{~mm}$. In this simulation, the $x$ direction is taken as the horizontal minimum principal stress direction, the $y$ direction is taken as the horizontal maximum principal stress direction, and the $z$ direction is taken as the vertical principal stress direction. This paper mainly studies the effect of angle change between perforation direction and horizontal minimum principal stress on hydraulic fracturing in shale reservoir, and the $\theta$ takes 0,15 , $30,45,60,75$, and 90, respectively. When establishing the perforation model, the direction with a certain angle with the $x$ axis can be set, then the perforation cross-section can be stretched along this direction to form perforation of different angles, and the perforation part can be named as the collection "Perforation."

Enter the Property module, create material attributes, and input various parameters: elastic modulus is $35 \mathrm{GPa}$, Poisson's ratio is 0.25 , mole Coulomb model, internal friction angle is 33.86 , cohesion $8.98 \mathrm{MPa}$, and permeability coefficient is $2 \times 10^{-9} \mathrm{~m} / \mathrm{s}$. After creating the material, set up defined cross-section attributes, and type is entity isotropy. Finally, cross-section attributes are assigned to the model. Next, enter the Assembly module and assemble the model. The assembled model is shown in Figure 4.

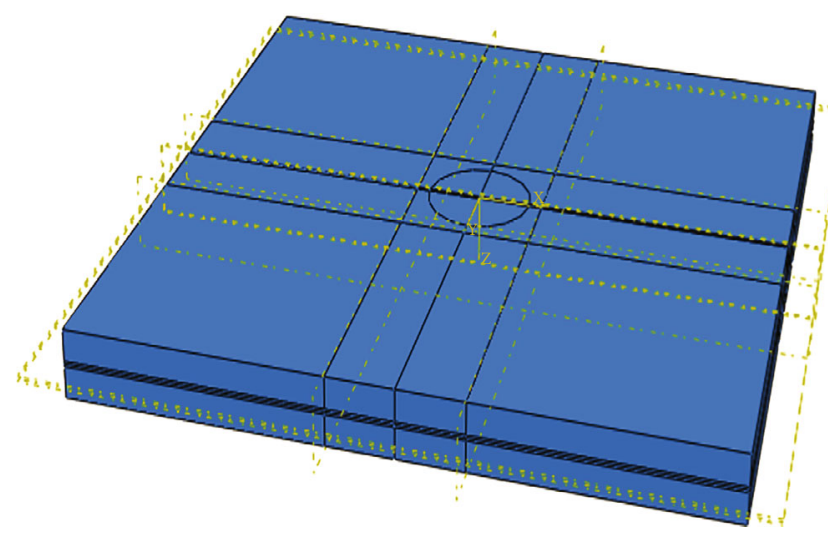

FIgURE 4: The assembled finite element model.

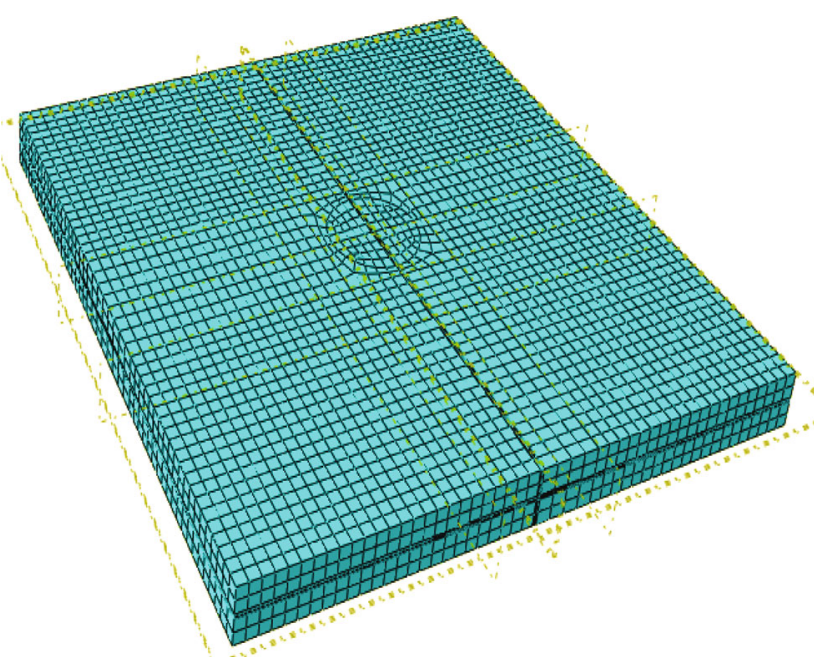

Figure 5: Finite element model after meshing.

Enter the Step module to establish the analysis step. This simulation needs two-step analysis. First, the in situ stress is balanced, and then the well digging and perforation are 

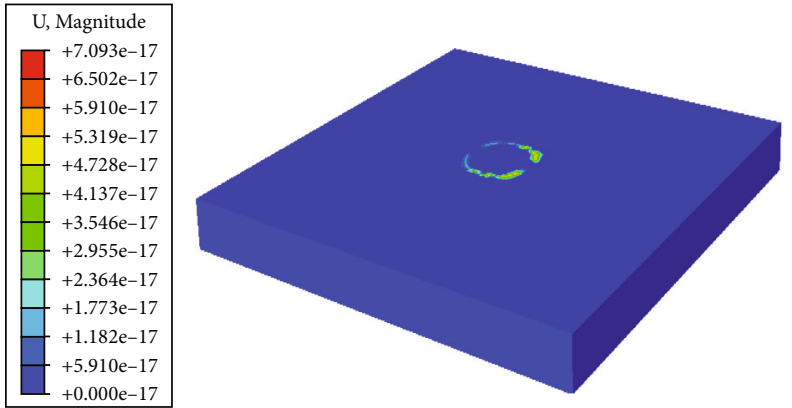

(a) Total displacement of $\theta=0^{\circ}$
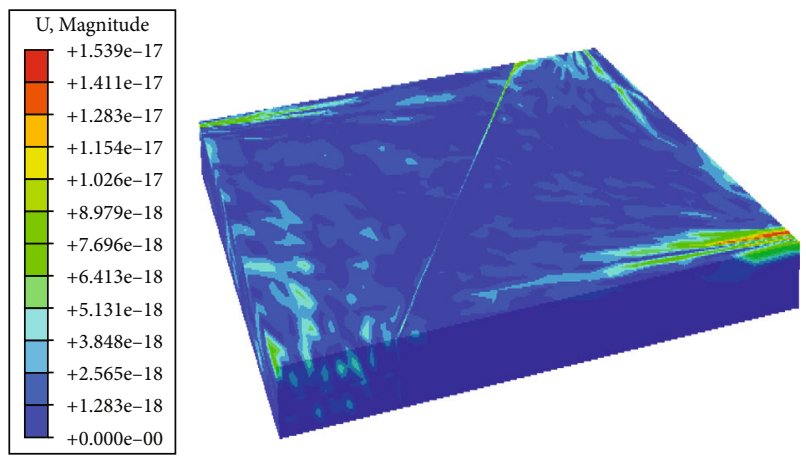

(c) Total displacement of $\theta=30^{\circ}$
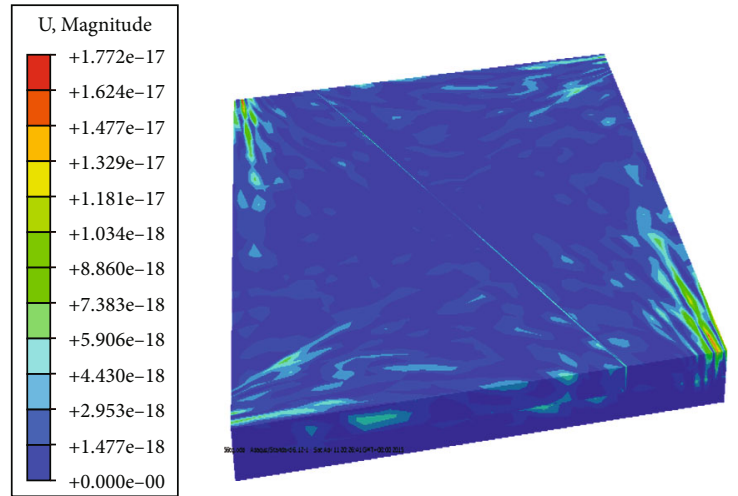

(e) Total displacement of $\theta=60^{\circ}$
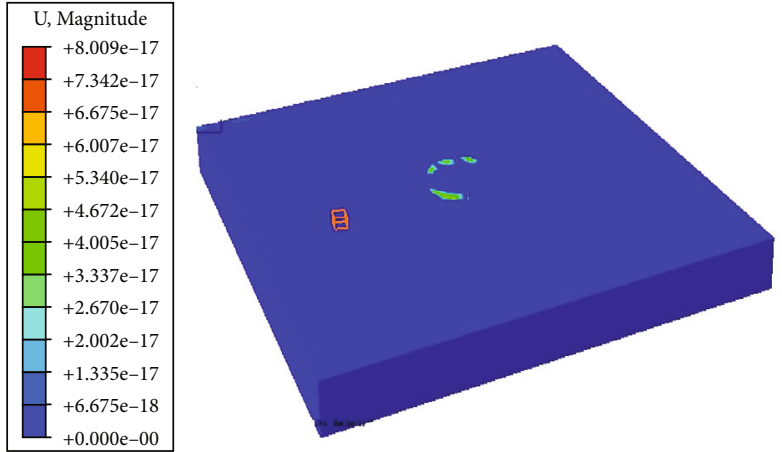

(b) Total displacement of $\theta=15^{\circ}$
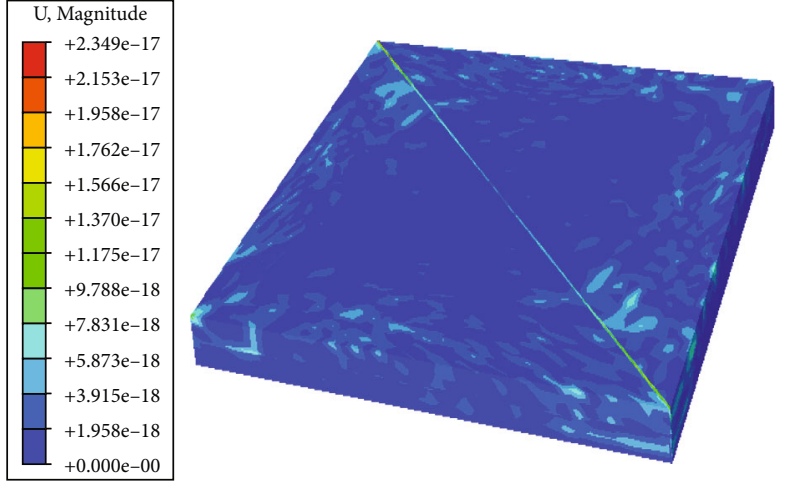

(d) Total displacement of $\theta=45^{\circ}$
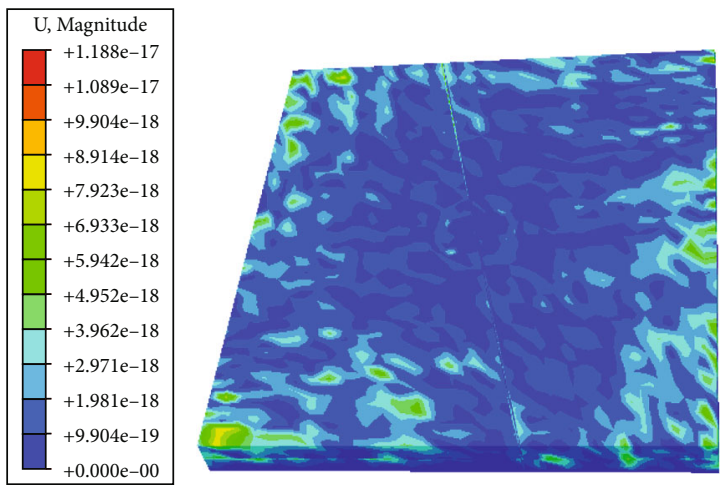

(f) Total displacement of $\theta=75^{\circ}$
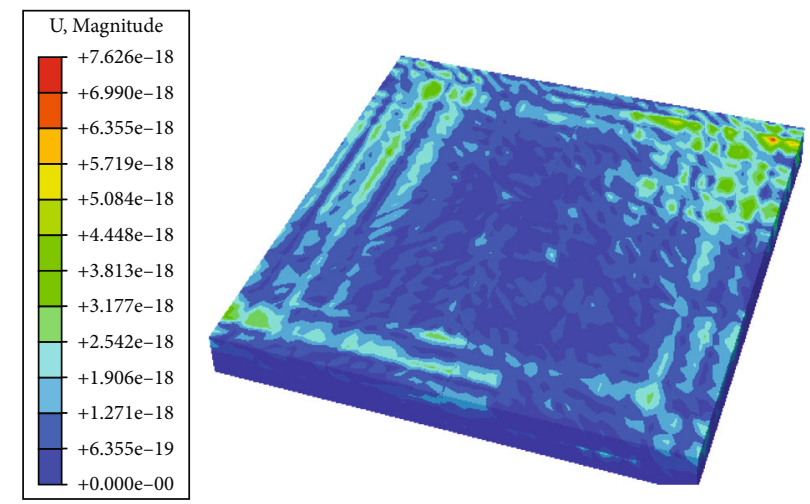

(g) Total displacement of $\theta=90^{\circ}$

FIgURE 6: Displacement nephogram of the model under different perforation angles after in situ stress balance. 

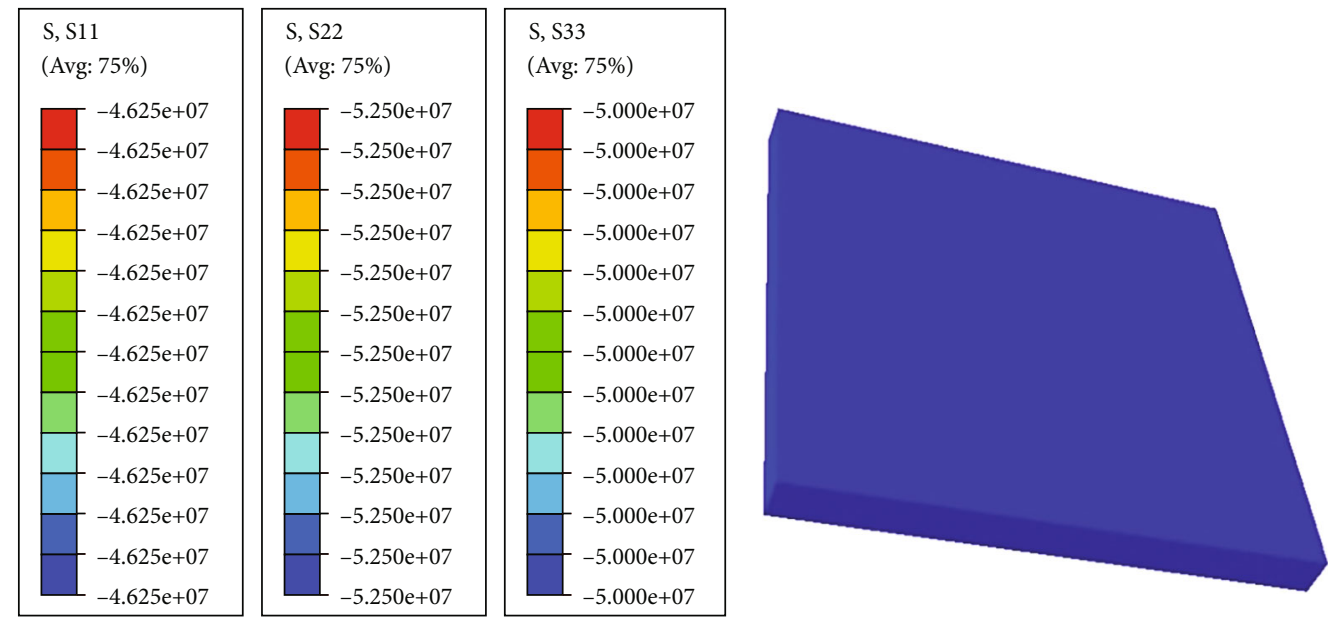

Figure 7: Stress nephograms in all directions (S11, S22, S33) after in situ equilibrium.

carried out after balance. Then, the pore water pressure is added to the perforation surface for fluid-solid coupling analysis. Perform the calculation of the first analysis step first and perform the calculation of the second analysis step after the calculation is successful. Therefore, the ground stress balance analysis step is established first, and the fluid-structure coupling analysis step will not be established temporarily. If the results obtained from the ground stress balance analysis step meet the requirements, the fluidstructure coupling analysis step is added. The order of displacement of soil should be less than $10^{-6}$ after ground stress balance. Create the geostatic analysis step and turn on the nonlinear button.

Boundary conditions and forces need to be applied to the model. Constrain the $Z$ direction displacement of the underside and the $X$ and $Y$ displacements of the sides. Due to the thin thickness of the reservoir, gravity is much less than other loads; so, the effect of gravity can be ignored. Enter the Mesh module to mesh the model. Before the division, it is necessary to cut the model for some parts of the model are not regular enough. The reference surface method is mainly used to cut the rules of each part of the model to divide the grid. The global grid density is 0.12 , the unit shape is hexahedral, and the structured grid division technology is adopted. The linear reduced integral element is more accurate in solving the displacement; so, the distortion of the grid has little effect on the analysis accuracy. For fluid-solid coupling analysis, the element used should have one more freedom than the conventional element; so, the linear reduced integral pore pressure element is used (C3D8RP). The grid is shown in Figure 5.

Define all nodes of the model as ALLNODES and all units of the model as ALLELE. Set the initial stress state and initial pore pressure in the keyword as follows: "*initial conditions, type=pore pressure", "Shale Reservoir -1.ALLNODES,26250000”, “*initial conditions, type=stress", and "Shale Reservoir -1.ALLELE,-46250000., $-52500000 .,-50000000 ., 0.0,0.0,0.0$ ”.

Then, the task submission calculation is established to balance the ground stress. If the order of magnitude of dis- placement is $10^{-6}$ after ground stress balance, it meets the requirements, and the calculation of the second analysis step can be carried out. Enter the Step module again, create fluidstructure coupling analysis step (soil), select the steady flow, set the initial analysis step to 0.01 , and use asymmetric solver. Then, set the output requirements of field variables, open the dialog box for editing output requirements of field variables, and add PEEQ (equivalent plastic strain) and FLVEL (seepage velocity) on the basis of the original output variables.

In order to conform to the actual situation, rigid body constraint is added on the surface of the well hole. Enter the interaction module, starting with a reference point at any point on the borehole surface, then click the create Constraints button, select the rigid body, select all the well surface with the mouse, and attach the rigid constraints to the well surface. In the fluid-structure interaction step, pore water pressure needs to be applied to the perforated surface. Firstly, enter the Mesh module and name the nodes on the perforating surface TUNNELNODES. Then, enter the Load module and apply pore water pressure of $60 \mathrm{MPa}$ on TUNNELNODES. The whole analysis process is firstly the balance of ground stress, then the excavation of wells and perforation, and finally the fluid-solid coupling. So, the unit life and death function of ABAQUS is used to remove the unit of well and perforation part to complete the simulation of well and perforation excavation. Add the following statement to the keywords: "*Model change, remove", "Shale Reservoir-1.Well", “*Model change, remove", "Shale Reservoir-1. Perforation".

At this point, the whole process is completed, and the task can be submitted after the establishment of the operation.

\section{Numerical Simulation of Fracturing Characteristics in Different Perforation Directions}

In this section, the influence of the angle between the perforation direction and the direction of the minimum principal 


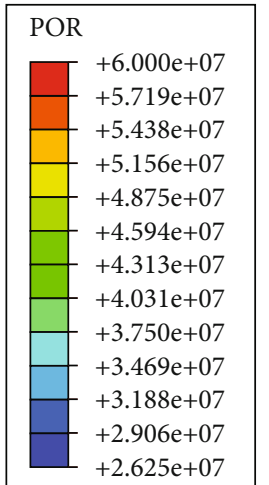

(a) Total displacement of $\theta=0^{\circ}$

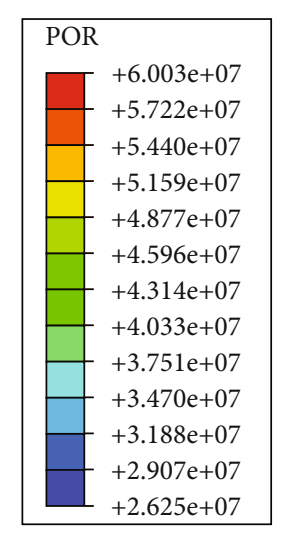

(c) Total displacement of $\theta=30^{\circ}$
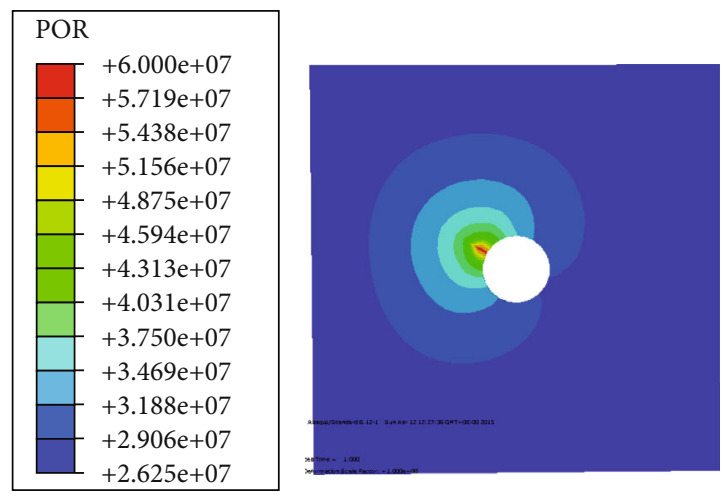

(e) Total displacement of $\theta=60^{\circ}$
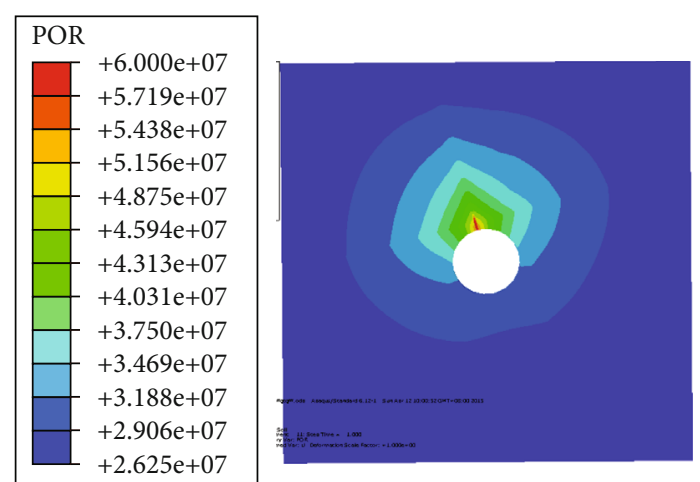

(b) Total displacement of $\theta=15^{\circ}$
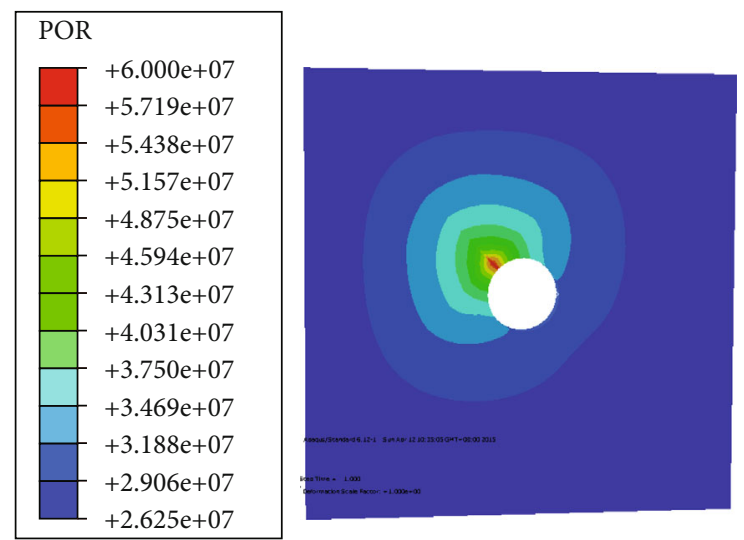

(d) Total displacement of $\theta=45^{\circ}$
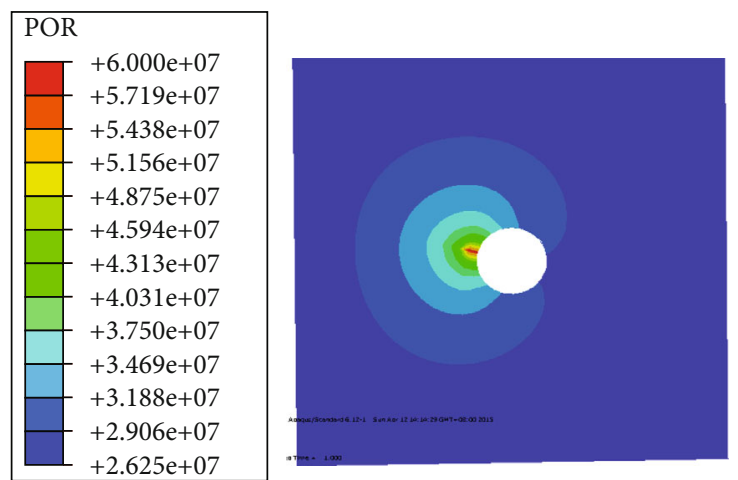

(f) Total displacement of $\theta=75^{\circ}$
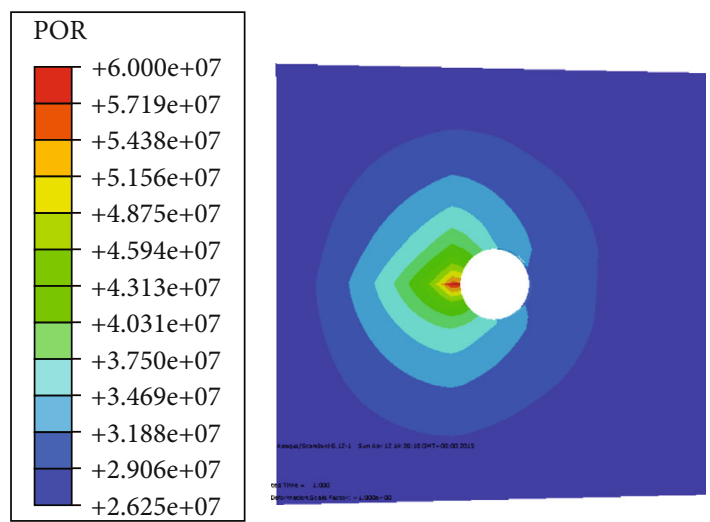

(g) Total displacement of $\theta=90^{\circ}$

Figure 8: Pore pressure nephogram under different perforation angles. 


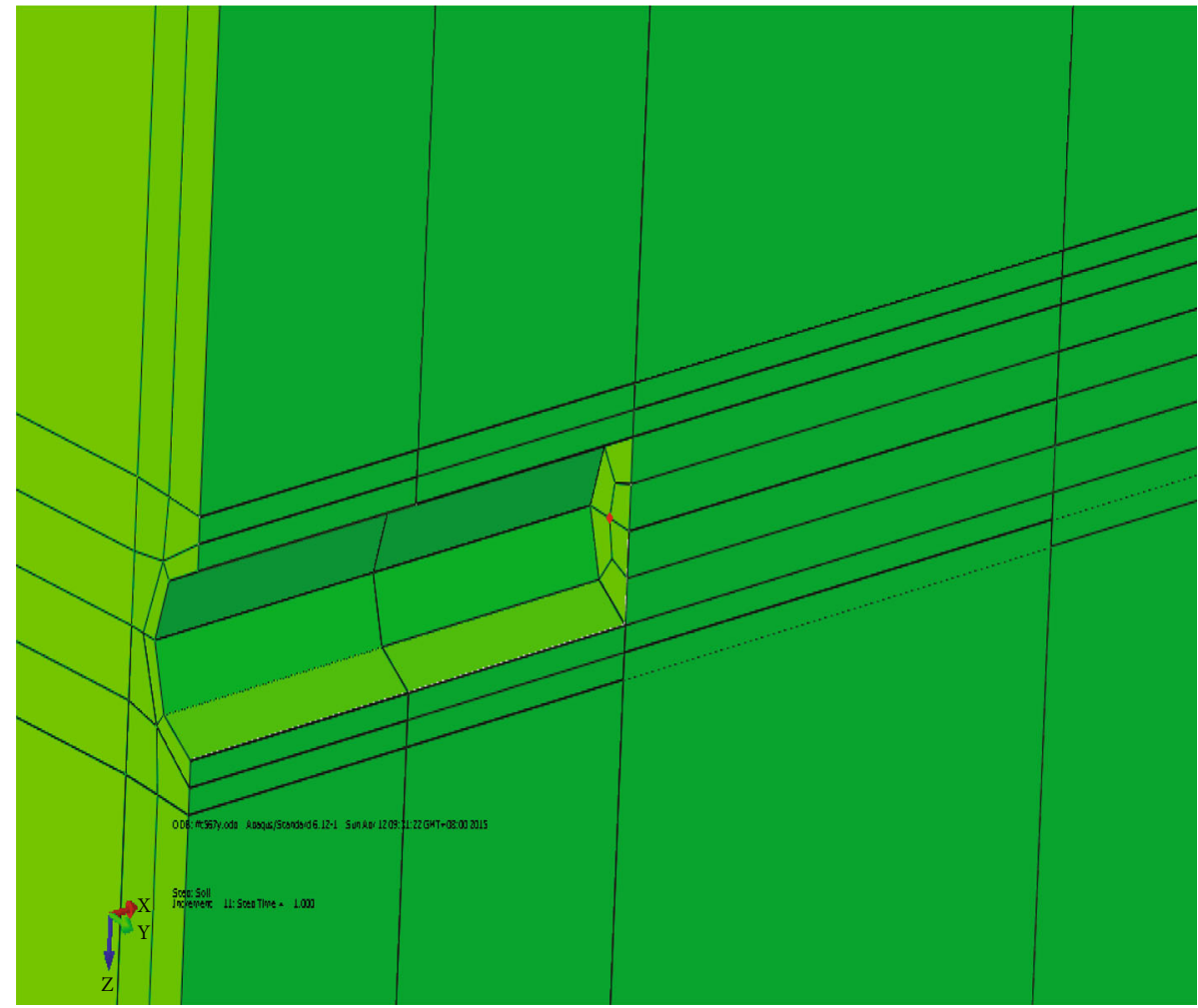

Figure 9: Location of test points.

stress on the hydraulic fracturing effect is studied. The values of $\theta=0^{\circ}$ are $0^{\circ}, 15^{\circ}, 30^{\circ}, 45^{\circ}, 60^{\circ}, 75^{\circ}$, and $90^{\circ}$, respectively. The geostress conditions are as follows: the horizontal minimum principal stress is $46.25 \mathrm{MPa}$ in the $x$ direction, the horizontal maximum principal stress is $52.5 \mathrm{MPa}$ in the $y$ direction, and $50 \mathrm{MPa}$ in the $z$ direction. According to the steps described in the above section, the material properties are defined, the analysis steps are set, the load and boundary conditions are applied, and the grid is divided and calculated. The ground stress equilibrium displacement results of each perforation angle are shown in Figure 6.

The displacement magnitude of each perforation angle model after stress balance is $10^{-17}$, far less than $10^{-6}$ and close to zero, and then the stress balance meets the requirements. The cloud images of S11, S22, and S33 each perforation angle model after geostress balance are consistent with the initial geostress conditions, as shown in Figure 7.

Through the above displacement and stress results in all directions, it is known that the calculation of stress equilibrium step is correct. Then, the excavation hole and perforation are carried out, and finally, the fluid-solid coupling analysis step is calculated. The resulting pore pressure distribution is shown in Figure 8. To facilitate observation of the pore water pressure and perforation angle at the perforation location, the model is cut in a plane perpendicular to the $z$-axis and in the middle of the reservoir thickness.

It can be seen from the pore pressure distribution cloud map of perforation from the above angles that the pore water pressure at the perforation is $60 \mathrm{MPa}$ and then gradu- ally decreases from the perforation to the surrounding area, which is $26.25 \mathrm{MPa}$ at the edge of the model. For the process of hydraulic fracturing of shale reservoirs, we mainly explore the fracture propagation at the front end of perforation. Therefore, the points at the same position at the front end of perforation are selected for each perforation model, and the maximum principal stress values of these points are compared to determine which perforation angle is most likely to crack the rock mass. The location of the selected observation point is shown in Figure 9.

Import the maximum principal stress data of this position point of each angle model into Excel and draw the curve of the maximum principal stress of each point with time as shown in Figure 10.

Through the curve in Figure 10, we can see that the maximum principal stress in the front of the perforation is the largest when the perforation is along the direction of the horizontal minimum principal stress, and when the maximum principal stress exceeds the tensile strength of the shale, cracks will occur and expand. When perforating along the direction of maximum principal stress, the maximum principal stress at the front of perforating is minimum. It can also be seen from Figure 10 that with the increase of perforation angle, the maximum principal stress at the front end of perforation gradually decreases. Therefore, when the perforation is along the direction of the horizontal minimum principal stress, the rock mass is most likely to rupture. In practical engineering, the perforation direction should be along the direction of the horizontal 


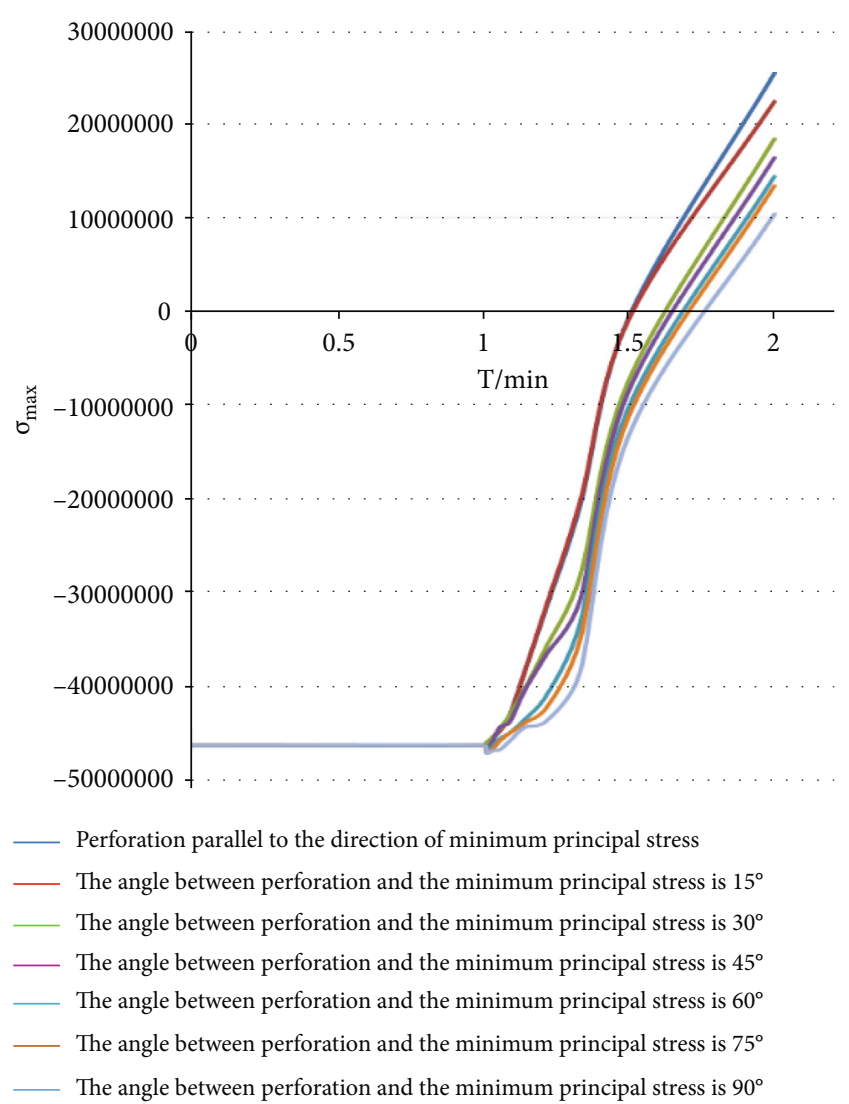

FIGURE 10: Curves of maximum principal stress changing with time in front of perforation at different angles.

minimum principal stress, so that hydraulic fracturing can achieve the best effect.

\section{Conclusion}

Low porosity and low permeability reservoirs, such as shale reservoir and tight sandstone reservoir, need fracturing to obtain production capacity. The selection of perforating parameters directly affects the fracturing effect and success rate of low porosity and low permeability reservoir. The perforation orientation affects the fracture pressure, fracture turning, and fracture morphology, which determines the success or failure of the volume fracturing. The conclusions are revealed through numerical research:

(1) When the ground stress conditions are equal, with the increase of perforation angle, the maximum principal stress at the front of perforation decreases gradually; that is, when the perforation is along the horizontal minimum principal stress, the maximum principal stress at the front of perforation is the largest; so, it is most conducive to the fracturing of shale reservoirs

(2) When the perforation is along the direction of the horizontal minimum principal stress and the horizontal stress difference is zero, the smaller the hori- zontal stress, the greater the maximum principal stress at the front of the perforation. Therefore, the smaller the horizontal stress, the more conducive to the fracture of shale reservoirs

(3) When the perforation is along the horizontal minimum principal stress, the maximum principal stress at the front end of the perforation increases with the increase of the horizontal stress difference. Therefore, the greater the horizontal stress difference, the more conducive to the rupture of shale reservoirs

\section{Data Availability}

The data used to support the findings of this study are included within the article.

\section{Conflicts of Interest}

The authors declare that they have no conflicts of interest.

\section{Acknowledgments}

This work was financially supported by the National Natural Science Foundation of China (41807254), China Postdoctoral Science Foundation (2020M682372), Young Talent Support Project of Henan Province (2021HYTP013), the Key Research \& Development and Promotion Projects of Henan Province (No. 212102310374), and Key Engineering Technology for Exploration and Development of Tight Gas in Northeastern Sichuan Basin of China (P21115).

\section{References}

[1] H. L. Matthews, G. W. Schein, and M. R. Malone, "Stimulation of gas shales: they're all the same-right," in Paper presented at the SPE Hydraulic Fracturing Technology Conference, College Station, Texas, USA, 2007.

[2] J. Omkar, B. Grieser, K. K. Chong, and A. Passman, "A completions roadmap to shale-play development: a review of successful approaches toward shale-play stimulation in the last two decades," in Paper presented at the International Oil and Gas Conference and Exhibition in China, Beijing, China, 2010.

[3] P. N. Mutalik and R. W. Gibson, "Case history of sequential and simultaneous fracturing of the Barnett shale in parker county," in Paper presented at the SPE Annual Technical Conference and Exhibition, Denver, Colorado, USA, 2008.

[4] Y. Z. Wang, B. Hou, D. Wang, and Z. H. Jia, "Features of fracture height propagation in cross-layer fracturing of shale oil reservoirs," Petroleum Exploration and Development, vol. 48, no. 2, pp. 469-479, 2021.

[5] W. John and R. Roger, "The shale shaker: an investor's guide to shale gas," Oil and Gas Investor, vol. 1, pp. 2-9, 2007.

[6] G. D. Vassilellis, C. Li, R. Seager, and D. Moos, "Investigating the expected long-term production performance of shale reservoirs," in Paper presented at the Canadian Unconventional Resources and International Petroleum Conference, Calgary, Alberta, Canada, 2010.

[7] S. C. Maxwell, T. I. Urbancic, N. Steinsberger, and R. Zinno, "Microseismic imaging of hydraulic fracture complexity in 
the barnett shal," in Paper presented at the SPE Annual Technical Conference and Exhibition, p. 77440, San Antonio, Texas, 2002.

[8] J. M. Zhang and X. F. Liang, "Impact of the shale gas revolution on the United States and the world," Petrochemical Technology and Economy, vol. 29, no. 4, pp. 8-14, 2013.

[9] R. Z. Huang, "Crack initiation and propagation by hydraulic fracturing," Petroleum Exploration and Development, vol. 5, 1981.

[10] J. Zhou, M. Chen, Y. Jin, and G. Q. Zhang, "Analysis of fracture propagation behavior and fracture geometry using a tri- axial fracturing system in naturally fractured reservoirs," International Journal of Rock Mechanics and Mining Sciences, vol. 45, no. 7, pp. 1143-1152, 2008.

[11] M. K. Fisher, B. M. Davidson, A. K. Goodwin, E. O. Fielder, and W. S. Buckler, "Integrating fracture mapping technologies to optimize stimulations in the Barnett Shale," in Paper SPE 77411 presented at the SPE Annual Technical Conference and Exhibition, San Antonio, Texas, 2002.

[12] S. C. Maxwell, T. I. Urbancik, and N. P. Steinsberger, "Microseismic imaging of hydraulic fracture complexity in the Barnett Shale," in Paper SPE 77440 presented at the SPE Annual Technical Conference and Exhibition, San Antonio, Texas, 2002.

[13] M. J. Mayerhofer, E. Lolon, N. R. Warpinski, C. L. L. Cipolla, D. Walser, and C. M. M. Rightmire, "What is stimulated reservoir volume?," SPE Production \& Operations, vol. 25, no. 1, pp. 89-98, 2010.

[14] Q. Wu, Y. Xu, Y. Z. Liu, Y. H. Ding, X. Q. Wang, and T. F. Wang, "The status quo of shale gas volume modification technology in the United States and its enlightenment to China," Petroleum Drilling and Production Technology, vol. 33, no. 2, pp. 1-7, 2011.

[15] H. P. Xie, F. Gao, Y. Ju, Q. Fu, and F. B. Zhou, "The unconventional theory and technical conception of shale reservoir fracturing," Journal of Sichuan University (Engineering Science Edition), vol. 6, no. 44, pp. 1-6, 2012.

[16] A. Al-Busaidi, J. F. Hazzard, and R. P. Young, "Distinct element modeling of hydraulically fractured Lac du Bonnet granite," Ornal of Geophysical Research: Solid Earth, vol. 110, no. B6, pp. 1978-2012, 2005.

[17] J. Adachi, E. Siebrits, A. Peirce, and J. Desroches, "Computer simulation of hydraulic fractures," International Journal of Rock Mechanics and Mining Sciences, vol. 44, no. 5, pp. 739757, 2005.

[18] J. Zhu, P. Ye, S. L. Wang, D. F. Xiao, and H. Wang, "Numerical simulation of three-dimensional dynamic fracture propagation in hydraulic fracturing of low permeability reservoirs," Journal of Petroleum, vol. 31, no. 1, pp. 119-123, 2010.

[19] M. Haddad and K. Sepehrnoori, "XFEM-Based CZM for the simulation of 3D multiple-cluster hydraulic fracturing in quasi-brittle shale formations," Rock Mechanics and Rock Engineering, vol. 49, no. 12, pp. 4731-4748, 2016.

[20] H. J. Wang, D. A. Liu, Z. D. Cui, C. Cheng, and Z. Jian, "Investigation of the fracture modes of red sandstone using XFEM and acoustic emissions," Theoretical and Applied Fracture Mechanics, vol. 85, pp. 283-293, 2016.

[21] F. Hamidi and A. Mortazavi, "A new three dimensional approach to numerically model hydraulic fracturing process," Journal of Petroleum Science and Engineering, vol. 124, pp. 451-467, 2014.
[22] C. H. Ahn, R. Dilmore, and J. Y. Wang, "Development of innovative and efficient hydraulic fracturing numerical simulation model and parametric studies in unconventional naturally fractured reservoirs," Journal of Unconventional Oil and Gas Resources, vol. 8, pp. 25-45, 2014.

[23] S. L. Montgomery, D. M. Jarvie, K. A. Bowker, and R. M. Pollastro, "Mississippian Barnett Shale, Fort Worth basin, north-central Texas: gas-shale play with multi-trillion cubic foot potential," AAPG Bulletin, vol. 89, no. 2, pp. 155-175, 2005.

[24] J. S. Yoon, G. Zimmermann, and A. Zang, "Numerical investigation on stress shadowing in fluid injection-induced fracture propagation in naturally fractured geothermal reservoirs," Rock Mechanics and Rock Engineering, vol. 48, no. 4, pp. 1439-1454, 2015.

[25] H. J. Wang, F. Zhao, Z. Q. Huang, Y. Yao, and G. Yuan, "Experimental study of mode-I fracture toughness for layered shale based on two ISRM-suggested methods," Rock Mechanics and Rock Engineering, vol. 50, no. 7, pp. 1933-1939, 2017.

[26] K. Wu and J. E. Olson, "Numerical investigation of complex hydraulic-fracture development in naturally fractured reservoirs," SPE Production \& Operations, vol. 31, no. 4, pp. 300309, 2016.

[27] A. Kissinger, R. Helmig, A. Ebigbo et al., "Hydraulic fracturing in unconventional gas reservoirs: risks in the geological system, part 2," Environmental Earth Sciences, vol. 70, no. 8, pp. 3855-3873, 2013.

[28] J. Li, C. Wang, Wang, and H. Y. Tian, "Environmental concerns in shale gas development," Environmental Protection in Oil and Gas Fields, vol. 22, no. 6, pp. 42-43, 2012.

[29] R. W. Howarth, R. Santoro, and A. Ingraffea, "Methane and the greenhouse-gas footprint of natural gas from shale formations," Climatic Change, vol. 106, no. 4, pp. 679-690, 2011.

[30] A. Burnham, J. Han, C. E. Clark, M. Wang, J. B. Dunn, and I. Palou-Rivera, "Life-cycle greenhouse gas emissions of shale gas, natural gas, coal, and petroleum," Environmental Science and Technology, vol. 46, no. 2, pp. 619-627, 2011.

[31] A. Mazzoldi, A. P. Rinaldi, A. Borgia, and J. Rutqvist, "Induced seismicity within geological carbon sequestration projects: Maximum earthquake magnitude and leakage potential from undetected faults," Green house Gas Control, vol. 10, pp. 434-442, 2012.

[32] J. W. Teng and Y. S. Liu, "Chinese shale gas accumulation and potential productivity and environmental pollution analysis," Chinese Geology, vol. 40, no. 1, 2013.

[33] M. Zoback, S. Kitasei, and B. Copithorne, Addressing the environmental risks from shale gas development, World Watch Institute, 2010.

[34] T. Coons and R. Walker, Community Health Risk Analysis of Oil and Gas Industry in Garfield County. Grand Junction, Saccommano Research Institute, CO, 2008.

[35] Q. X. Zhang, B. Hou, B. T. Lin, X. Liu, and Y. Gao, "Integration of discrete fracture reconstruction and dual porosity/dual permeability models for gas production analysis in a deformable fractured shale reservoir," Journal of Natural Gas Science and Engineering, vol. 93, article 104028, 2021.

[36] Z. J. Zhao, H. J. Wang, Z. D. Cui et al., "Experimental study on mode-I fracture toughness using chevron straight-notched semi-circular bend (CSNSCB) method," Theoretical and Applied Fracture Mechanics, vol. 116, article 103093, 2021. 
[37] S. H. Fallahzadeh, V. Rasouli, and M. Sarmadivaleh, "An investigation of hydraulic fracturing initiation and nearwellbore propagation from perforated boreholes in tight formations," Rock Mechanics and Rock Engineering, vol. 48, no. 2, pp. 573-584, 2021.

[38] L. M. McKenzie, R. Z. Witter, L. S. Newman, and J. L. Adgate, "Human health risk assessment of air emissions from development of unconventional natural gas resources," Science of the Total Environment, vol. 424, pp. 79-87, 2012.

[39] H. J. Wang, J. Li, F. Zhao, J. Dong, Y. Cui, and W. Gong, "Experimental study of volumetric fracturing properties for shale under different stress states," Geofluids, vol. 2021, Article ID 6650710, 16 pages, 2021.

[40] X. C. Wang, Finite Element Method, Tsinghua University Press, Beijing, 2003.

[41] K. Fei and J. W. Zhang, Application of Abaqus in geotechnical engineering, China Hydroelectric Press, Beijing, 2009.

[42] J. C. Wang and Y. Chen, Application of Abaqus in civil engineering, Zhejiang Zhejiang University Press, 2006. 